\title{
EKOLOGI BUDAYA DAN TRADISI : HIDUP DI DALAM RUANG ARSITEKTUR MULTI ETNIS
}

\author{
Varianotto Sanjaya $^{1)}$, Maria Veronica Gandha ${ }^{2)}$ \\ 1)Program Studi S1 Arsitektur, Fakultas Teknik, Universitas Tarumanagara, varianotto@gmail.com \\ 2) Program Studi S1 Arsitektur, Fakultas Teknik, Universitas Tarumanagara, mariag@ft.untar.ac.id
}

\begin{abstract}
ABSTRAK
Manusia merupakan makhluk sosial yang didefinisikan sebagai, mahkluk hidup yang membutuhkan kehadiran orang lain secara langsung atau tidak langsung. Dimana manusia dalam kehidupannya tidak dapat hidup sendiri dan memerlukan individu kedua, ketiga, dan seterusnya untuk melakukan aktivitas sehari-hari, yang terjadi secara beruntun, mengakibatkan kebiasaan dan menjadi aturan yang diturun temurunkan untuk menjaga "wajah" atau "nilai" dari sebuah kelompok, yang merupakan salah satu cabang dari struktur ekologi sosial yang ada pada era modernisasi ini, yang disebut sebagai tradisi dan kebudayaan. Keragaman budaya dan seni yang dimiliki bangsa Indonesia merupakan salah satu anugerah dari Tuhan Yang Maha Esa. Dengan hasil kekayaan (Budaya dan tradisi) ini membuktikan bahwa keanekaragaman telah terjadi Indonesia adalah negara yang majemuk, begitu kekayaan budayanya sekaligus memiliki ribuan identitas kedaerahan. Oleh karena itu, memang demikian adanya rasa kebanggaan dengan bangsa Indonesia yang majemuk budaya,dimana dengan keaneragamannya, tetap terjadi persatuan dan kesatuan yang erat dengan berbagai macam suku dan etnis yang ada. . Bintan memiliki kekayaan alam serta potensi pariwisata yang tinggi di bidang sosial,budaya dan alam. Bintan merupakan salah satu pulau terbesar yang berada di provinsi Kepulauan Riau (Segantang Lada). Daerah Kepulauan ini juga disebut dengan bumi melayu karena daerah ini dulunya merupakan dibawah kekuasaan kerajaan riau-lingga dimana rajanya merupakan orang melayu. Selain melayu, Bintan memiliki budaya dan tradisi dari suku lain yang ikut serta dalam pengembangan dan pertumbuhan pembangunan dan marsyarakatnya yaitu bangsa Orang Suku Laut (Proto Melayu) dan etnis Tiong Hoa. Seiring waktu kebiasaan dan budaya turun temurun dari generasi ke generasi semakin menurun, maka perancangan Arsitektur ini bertujuan untuk menambahkan dan mengajarkan ilmu dan sejarah atas tradisi dan budaya yang ada didalam Bintan, serta memancarkan gaya arsitektur dari suku-suku tersebut kedalam satu gaya yang baru yang dipengaruhi oleh gaya arsitektur organik, serta mempertimbangka lingkungan ekosistem sekitar, dalam memperkaya suasana atau menambahkan cita rasa lingkungan sekitar. Dengan Rancangan ini yang bertujuan untuk mengembangkan dan memperkenalkan serta mempreservasikan kebudayaan dan tradisi yang ada di pulau Bintan. Proses Perancangan pada desain ini adalah, melakukan analisa terhadap permasalahan yang dihadapi, sehingga mengeluarkan gagasan atau ide untuk pemograman yang sesuai dengan permasalahan. Program Utama kemudian di sesuaikan dengan tapak yang terpilih atas kriteria - kriteria yang ada, sehingga dapat membuahkan hasil rancangan yang membentuk atau menambahkan nilai pada lingkungan tapak.
\end{abstract}

\section{Kata kunci: Budaya ; Ekosistem ; Etnis ; Lingkungan ; Tradisi}

\begin{abstract}
Humans are social creatures that are defined as living things that need the presence of other people directly or indirectly. Where as humans are creatures that couldn't live alone and therefore, is in need of a second, third, or more individuals to carry out daily activities, which occur in succession, resulting in habits and become rules passed down from generation to generation to maintain the "face" or "value" of a group, which is one of the branches of the social ecological structure that exists in this modernization era, which is known as tradition and culture. The diversity of cultures and arts possessed by the Indonesian people is one of the gifts from the One Above All. With the results of this wealth (culture and tradition) it
\end{abstract}


proves that diversity has occurred. Indonesia is a pluralistic country, so rich in culture as well as having thousands of regional identities. Therefore, it is true that there is a sense of pride in the Indonesian nation which is culturally diverse, with its diversity, there is still a strong unity and unity with the various existing tribes and ethnicities. . Bintan has natural wealth and high tourism potential in the social, cultural and natural fields. Bintan is one of the largest islands in the Riau Islands province (Segantang Lada). This archipelago area is also called the birthplace of Malay because this area used to be the Kingdom of Riau-Lingga, where the king was a Malay person. Apart from being Malay, Bintan has the culture and traditions of other tribes that participate in the development and growth of development and its community, namely the people of the Sea Tribe (Proto Melayu) and the Tiong Hoa ethnicity. Over time the customs and culture passed down from generation to generation, this architectural design aims to add and teach knowledge and history of the traditions and culture that exist within Bintan, and transmit the architectural styles of these tribes into a new style that influenced by the organic architectural style, as well as taking into account the environment of the surrounding ecosystem, in enriching the atmosphere or adding a taste to the surrounding environment. The design process in this design is to analyze the problems encountered, so as to issue ideas or ideas for programming that are in accordance with the problem. The Main Program is then adjusted to the selected site based on the existing criteria, so that it can produce design results that form or add value to the site environment.

\section{Keywords: Culture ; Ecosystem ; Enviroment ; Ethnicity ; Tradition.}

\section{PENDAHULUAN}

\section{Latar Belakang}

Manusia merupakan makhluk sosial yang didefinisikan sebagai, mahkluk hidup yang membutuhkan kehadiran orang lain secara langsung atau tidak langsung. Dimana manusia dalam kehidupannya tidak dapat hidup sendiri dan memerlukan individu kedua, ketiga, dan seterusnya untuk melakukan aktivitas sehari-hari, yang terjadi secara beruntun, mengakibatkan kebiasaan dan menjadi aturan yang diturun temurunkan untuk menjaga "wajah" atau "nilai" dari sebuah kelompok, yang merupakan salah satu cabang dari struktur ekologi sosial yang ada pada era modernisasi ini, yang disebut sebagai tradisi dan kebudayaan.

Kebudayaan dapat diartikan sebagai keseluruhan pengetahuan manusia sebagai makhluk sosial yang digunakannya untuk memahami dan menginterpretasi lingkungan dan pengalamannya, serta menjadi pedoman bagi tingkah lakunya. Suatu kebudayaan adalah milik bersama anggota suatu masyarakat atau suatu golongan sosial, yang disebarkan kepada anggota-anggotanya dan diwariskan kepada generasi berikutnya melalui proses belajar dan dengan menggunakan simbolsimbol yang terwujud dalam bentuk yang terucapkan maupun yang tidak (termasuk juga berbagai peralatan yang dibuat oleh manusia). Tradisi dan kebudayaan sering dikaitkan dengan hal-hal berbau mistis dan tabu.

Sedangkan Tradisi dipahami sebagai segala sesuatu yang bersifat turun temurun dari nenek moyang. Tradisi dalam kamus antropologi sama dengan adat istiadat yakni kebiasaan yang bersifat magis religius dari kehidupan suatu penduduk asli yang mencakupi nilai-nilai budaya, norma-norma, hukum dan aturan-aturan yang saling berhubungan, dan kemudian menjadi suatu sistem atau aturan yang sudah dimatangkan serta mencakup segala konsep sistem budaya dari suatu kebudayaan untuk mengatur tindakan atau perbuatan manusia dalam kehidupan sosial melalui ketakutan, rasa malu, atau rasa bersalah.

Tradisi dan kebudayaan sering diintrepetasikan sebagai aturan yang tidak dapat diganggu gugat (menambahkan, mengurangi, menggabungkan, dll) oleh masyarakat pada era sekarang, 
sehingga tidak ada perkembangan yang terjadi, yang berujung pada pudar- nya tradisi dan kebudayaan itu sendiri. Permasalahan yang dihadapi kedua aspek tersebut meliputi :
a. Percepatan dunia (globalisasi dan industri).
b. Perselisihan antar etnis.
c. Penutupan diri dari perkembangan zaman 4. Berpindahnya penduduk.
d. Faktor eksternal (budaya, tradisi, kebiasaan daerah/negara asing).

Keragaman budaya dan seni yang dimiliki bangsa Indonesia merupakan salah satu anugerah dari Tuhan Yang Maha Esa. Dengan hasil kekayaan (budaya dan tradisi) ini membuktikan bahwa keanekaragaman telah terjadi Indonesia adalah negara yang majemuk, begitu kekayaan budayanya sekaligus memiliki ribuan identitasdari daerah nya. Oleh karena itu, memang demikian adanya rasa kebanggaan dengan bangsa Indonesia yang majemuk budaya, dimana dengan keanekaragamannya, tetap terjadi persatuan dan kesatuan yang erat dengan berbagai macam suku dan etnis yang ada.

Seni budaya dan tradisi yang ada di dalam Indonesia memiliki ciri khas di daerahnya masingmasing, salah satunya adalah seni budaya dan tradisi yang terdapat di pulau Bintan Kepulauan Riau. Bintan memiliki kekayaan alam serta potensi pariwisata yang tinggi di bidang sosial,budaya danalam. Bintan merupakan salah satu pulau terbesar yang berada di provinsi Kepulauan Riau (Segantang Lada). Daerah Kepulauan ini juga disebut dengan bumi melayu karena daerah ini dulunya terdapat kekuasaan kerajaan riau-lingga, dimana rajanya merupakan orang melayu. Selain melayu, Bintan memiliki budaya dan tradisi dari suku lain yang ikut serta dalam pengembangan dan pertumbuhan pembangunan dan marsyarakatnya yaitu bangsa Orang Suku Laut (Proto Melayu) dan etnis Tiong Hoa.

Dari waktu ke waktu, terjadi pemudaran budaya dan tradisi tersebut, dimulai dari bangsa Orang Suku Laut (OSL), yang mengalami pergeseran atas kedatangannya bangsa Deutro Melayu (Melayu) yang mengakibatkan masyarakat Orang Suku Laut untuk berpindah ke daerah pesisir, dimana mereka terletak jauh dari aktivitas utama kota (Perdagangan, Pemerintahan dan Pendidikan), sehingga terbelakangi dari percepatan yang terjadi didalam era tersebut.

Pada waktu sekarang, dimana percepatan yang terjadi di era globalisasi dan industri yang disertai dengan perkembangan teknologi yang pesat, telah merubah gaya dan kebiasaan masyarakat yang telah terjadi selama ribuan tahun, dimana nilai-nilai leluhur sudah lama terlupakan dan tersisihkan.

\section{Rumusan Masalah}

Terjadi-nya perselisihan dan kompetisi antar suku pada awal peradaban, memaksa suku yang karakteristiknya lebih submisif untuk mundur, sehingga garis warisan, baik dalam keturunan, tradisi maupun budaya semakin menipis seiring percepatan yang terjadi dan memuncak tingkat kepudaran atas nilai - nilai dasar yang ditemurunkan oleh leluhur Ketika percepatan globalisasi dan teknologi terjadi, yang mengakibatkan beberapa miskonsepsi atas tradisi dan budaya yang ada pada masyarakat warga Bintan. Dalam pulau Bintan, sudah tidak terlihat lagi bangunan yang mempresentasikan ketiga budaya tersebut, rumah dan bangunan tradisional setempat sudah tidak dipreservasi ataupun di jaga. Menghasilkan pertanyaan isu sebagai berikut :

- Bagaimana memperkenalkan budaya Bintan kepada masyarakat setempat maupun asing ?

- Bagaimana ekosistem kebudayaan diimplementasikan kedalam bentuk arsitektur?

- Bagaimana rancangan dapat meningkatkan rasa kepedulian serta menjadi wajah dari kebudayaan yang telah diungkit? 


\section{Tujuan}

Proyek ini bertujuan untuk mempreservasi kebudayaan dan tradisi yang ada, alkulturasi ketiga suku secara arsitektural, menggabungkan kebudayaan dan tradisi yang ada pada percepatan globalisasi dan industri dan mengajarkan kepada masyarakat dalam Bintan untuk menghargai, tertarik, membantu mengembangkan, menaikkan pengunjung pada sektor pariwisata Kepulauan Riau, terutama pada Bintan - Tanjung Pinang untuk masa yang akan datang, serta menjadi activator bagi Fusion/Hybrid dalam pemograman, aktivitas melalui system yang didukung oleh bangunan arsitektural.

\section{KAJIAN LITERATUR}

\section{Pengertian Ekologi, Ekosistem dan Beyond Ecology}

Ekologi berasal dari bahasa Yunani oikos (rumah atau tempat hidup) dan logos (ilmu). Secara literal ekolog adalah ilmu yang mempelajari tentang organisme dalam lingkungan hidupnya atau dengan kata lain mempelajari interaksi timbal - balik antara mahkluk hidup dengan lingkungannya. Ekologi hanya bersifat eksploratif bukan sesuatu yang bersifat eksperimental, jadi hanya mempelajari apa yang ada dan apa yang terjadi di lingkungan.

Menurut Zoer'aini (2003), Seseorang yang memplejari tentang ekologi yang mempertanyakan berbagai hal antara lain adalah:

a. Bagaimana alam bekerja.

b. Bagaimana spesies beradaptasi terhadap lingkunganya.

c. Apa yang diperlukan oleh mahkluk hidup pada habitatnya untuk melangsungkan kehidupannya.

d. Bagaimana mahkluk hidup mencukupi kebutuhannya atas materi dan energi.

e. Bagaimana cara interaksi antar organisme dalam lingkungan.

f. Bagaimana individu - individu dalam spesies dapat berfungsi dan teratur sebagai sebuah ekosistem.

g. Bagaimana estetika ekosistem tercipta.

Dari perpaduan antara harafiah dan berbagai kajian, maka ekologi dapat disebut sebagai ilmu yang mempelajari seluruh pola konektitivitas timbal - balik antar mahkluk hidup dan juga antara organisme dengan lingkungannya. Manusia yang disebut sebagai mahkluk hidup juga menjadi pembahasan dalam kajian ekologi. Ekologi menjadi jalan konektivitas antara ilmu alam dengan ilmu pengetahuan sosial. Ekologi dapat dibagi menjadi 2, yaitu:

a. Autekologi merupakan ilmu yang mempelajari konektivitas timbal balik suatu jenis organisme terhadap lingkungannya yang pada umumnya bersifat eksperimental dan induktif.

b. Sinekologi membahas golongan atau kelompok mahkluk hidup yang berinteraksi bersama sebagai satu kesatuan, yang bersifat filosofis, deduktif dan umumnya deskriptif.

\section{Ekologi dalam Kebudayaan}

Ekologi merupakan studi tentang interaksi antara makhluk hidup dan lingkungannya. Ekologi manusia adalah studi tentang hubungan dan interaksi antar manusia, biologi mereka, kebudayaan mereka, dan lingkungan fisik mereka. Istilah dengan judul Human Ecology, jurnal terkemuka pada bidangnya. Ekologi manusia mencakup antropologi ekologi (yang mencakup banyak ilmu biologi antropologi) dan antropologi lingkungan (sisi bidang yang lebih "budaya" atau yang lebih bersifat kemanusiaan). 
Ahli ekologi manusia mempelajari tentang banyak kriteria budaya dan lingkungannya, termasuk bagaimana dan mengapa budaya melakukan apa yang mereka lakukan untuk memecahkan masalah kebutuhan hidup mereka, bagaimana caranya sekelompok orang memahami lingkungan mereka, dan bagaimana mereka berbagi pengetahuan tentang lingkungan. Bidang luas ekologi manusia mencakup dua hal dari sub - divisi utama.

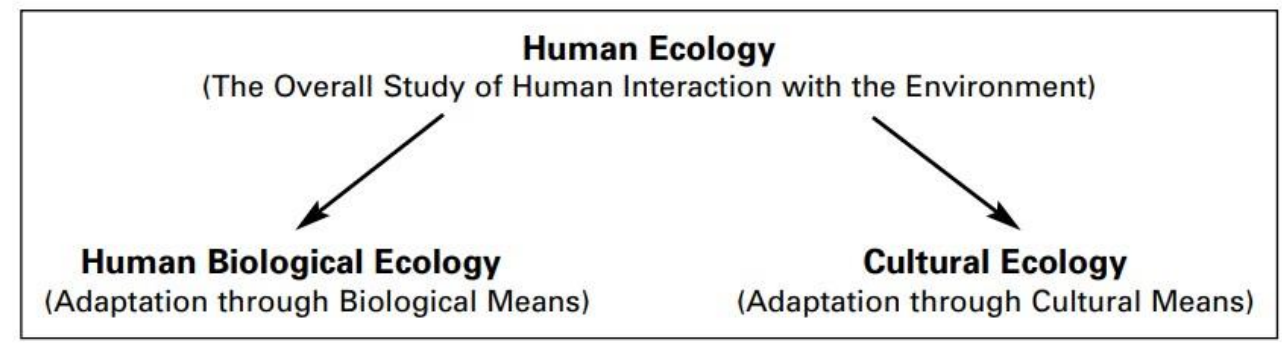

Gambar 1. Diagram Alir Ekologi Manusia.

Ahli ekologi manusia mempelajari tentang banyak kriteria budaya dan lingkungannya, termasuk bagaimana dan mengapa budaya melakukan apa yang mereka lakukan untuk memecahkan masalah kebutuhan hidup Ekologi Kebudayaan adalah studi tentang cara budaya digunakan oleh individual untuk beradaptasi dengan lingkungan mereka.

\section{Antropologi budaya}

Antropologi kebudayaan, termasuk antropologi sosial atau sosiokultural, adalah ilmu yang mempelajari tentang masyarakat dan budaya yang ada. Antropologi budaya mempelajari dua jenis studi utama: etnografi, studi tentang kelompok tertentu pada suatu kelompok tertentu waktu, dan etnologi, studi komparatif budaya. Antropologi budaya berusaha untuk mempelajari tentang semua hal yang terkait tentang suatu budaya, seperti sistem kekerabatan, aturan pernikahan, ekonomi, bahasa, politik dan lain - lain.

\section{Ekologi Budaya}

Dalam ilmu yang mempelajari tentang ekologi biologis manusia dapat memberi tahu kita banyak hal tentang cara adaptasi manusia, aspek budaya dari adaptasi harus dikaji melalui budaya ekologi. Fleksibilitas respons adaptif manusia membutuhkan studi tentang cara belajarnya manusia, cara mereka bersosialisasi, tingkat kecerdasan, dan kebutuhan dasar untuk membantu memahami bagaimana orang dan budaya dapat menghadapi dan menemukan solusi terhadap masalah sehari-hari mereka. Ekologi budaya adalah ilmu yang menjelaskan bagaimana dan mengapa budaya dapat beradaptasi dengan satu cara dan bukan dengan cara lain Pada hakikatnya budaya itu sendiri merupakan mekanisme adaptif. Budaya mengandung sejumlah elemen, seperti sistem sosial dan politik, pola permukiman, dan teknologi dan penyimpanan yang adaptif dalam bentuknya dan berkembang seiring perubahan lingkungan. 


\section{Alkulturasi}

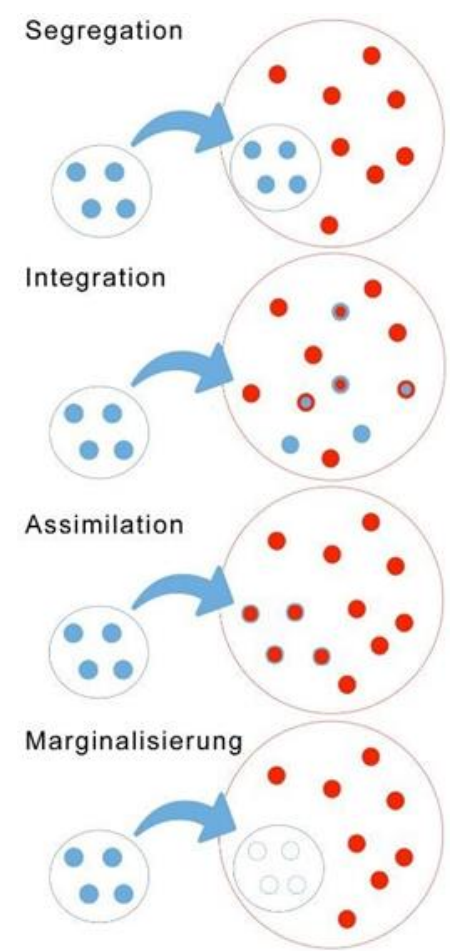

Gambar 2. Pola Interaksi Tipe Hubungan antar Perilaku.

Sekilas tentang konsep akulturasi (Prawati, 2010) bahwa akulturasi sebagai proses sosial yang terjadi ketika sekelompok orang dengan tertentu budaya dihadapkan dengan unsur asing budaya sedemikian rupa, sehingga ada unsur asing budaya secara bertahap diterima dan diproses menjadi mereka budaya sendiri tanpa kehilangan kepribadian itu budaya sendiri. Dalam hal ini ada perbedaan antara budaya sulit untuk diubah dan dipengaruhi oleh unsur budaya asing (budaya terselubung), dengan sayap budaya yang mudah menguap dan dipengaruhi oleh unsur budaya asing (budaya terbuka). Tersembunyi budaya misalnya:

- Sistem nilai budaya,

- Kepercayaan agama dianggap sakral,

- Beberapa adat istiadat yang telah dipelajari sejak awal proses sosialisasi individu,

- Beberapa bea cukai yang memiliki fungsionalitas yang lengkapdalam masyarakat.

\section{Arsitektur Tradisional}

Arsitektur merupakan pernyataan ruang dan waktu sepanjang kehidupan masyarakat yang beradab, yang menjadi wadah bagi segala aktivitas kehidupan masyarakat. Kegiatan masyarakat membutuhkan wadah ruang. Ini adalah aktivitas keseharian masyarakat beradab yang beragam, yang kesemuanya membutuhkan ruang atau tempat untuk melakukan aktivitas ini. Suprijanto mengungkapkan bahwa adat adalah tradisi, sesuatu yang diwariskan, disinilah proses penyampaian aturan atau aturan tradisi disesuaikan dengan keadaan atau zaman, sehingga perubahan secara inheren penting.

Arsitektur tradisional merupakan salah satu unsur budaya yang tumbuh dan berkembang seiring dengan berkembangnya suatu suku atau bangsa. Secara tradisional, arsitektur ideal memanifestasikan dirinya dalam bentuk terintegrasi, bentuk sosial dan material yang membentuk budaya daerah. Konteks budaya tradisional dalam arsitektur dapat dilihat dari aspek fisik dan non fisiknya. Aspek fisik justru menjadi prioritas daftar terakhir, sedangkan aspek 
non fisik diutamakan sebagai proses pembangunan rumah, berdasarkan ritual atau kepercayaan agama, yang lebih mengutamakan keabsahan dunia nyata dan alam yang lebih tinggi.

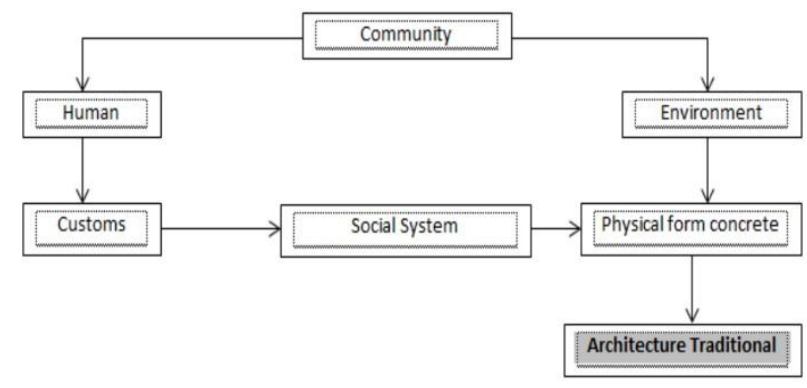

Gambar 3. Skema Konsep Perancangan Arsitektur Tradisional.

Rumah adat merupakan perwujudan budaya, nilai-nilai budaya akan diekspresikan dan diaplikasikan dalam seni arsitektur. Arsitektur merupakan perwujudan nilai budaya, baik nilai budaya individu maupun masyarakat.

\section{METODE}

\section{Metode Perancangan}

Proses Perancangan pada desain ini adalah, melakukan analisa terhadap permasalahan yang dihadapi, sehingga mengeluarkan gagasan atau ide untuk pemograman yang sesuai dengan permasalahan. Program Utama kemudian di sesuaikan dengan tapak yang terpilih atas kriteria - kriteria yang ada, sehingga dapat membuahkan hasil rancangan yang membentuk atau menambahkan nilai pada lingkungan tapak.

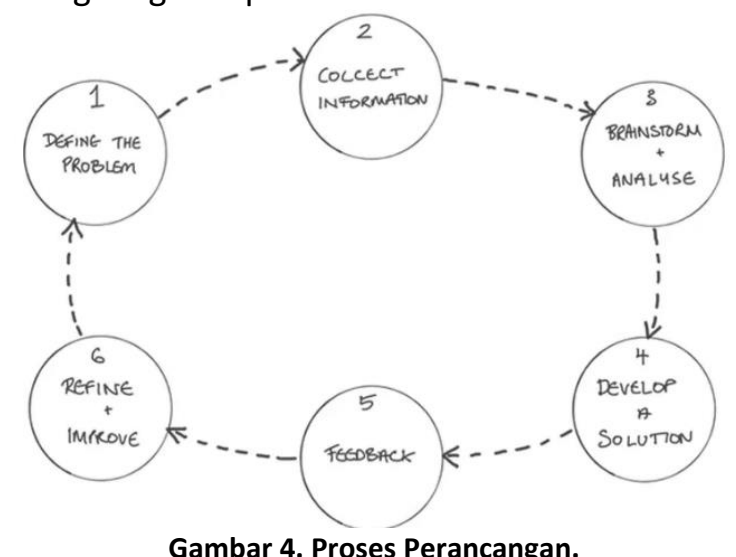

Metode ini dilakukan dengan mengambil atau mengumpul data - data mengenai permasalahan yang ada pada lingkungan Bintan, Kepulauan Riau, Indonesia, dimana data - data yang ada merupakan hasil dari pencarian melalui media internet atau online, serta wawancara dengan kerabat maupun teman. Setelah data dikumpulkan, maka akan dianalisa untuk mencari kebiasaan dari aktivitas keseharian masyarakat etnis - etnis tersebut serta budaya yang diwariskan, maupun yang tidak diwariskan, diketahui faktor - faktor pendukung dan yang menantang korelasi antar suku maupun dalam peradaban masa sekarang, sehingga dapat mendapatkan kesimpulan, atas program utama yang akan diusulkan, serta program pendukung, pada tapak yang akan dipilih setelah kriteria - kriteria telah di ketemukan. Setelah itu akan mask kedala proses rancangan, yang akan dirancang sesuai dengan arah mata angin, orientasi bangunan, orientasi tapa, matahari, pencahayaan, vegetasi, sirkulasi udara, sirkulasi ruang, sirkulasi transportasi, sirkulasi manusia, dll yang akan melewati beberapa gubahan dan eksperimen untuk mendapatkan hasil gubahan atau rancangan yang paling sesuai dengan program. 


\section{DISKUSI DAN HASIL}

\section{Kriteria Pemilihan Tapak}

a. Terlelak pada kawasan dengan kepadatan lalu - lintas yang relatif cukup tinggi.

b. Terletak pada area kota yang dapat diakses oleh beberapa suku yang disinggung dalam topik pembahasan (Tiong-Hoa, Suku Laut, Melayu)

c. Bangunan yang memiliki area pendukung seperti kemamanan, akses domestik \& internasional, area hiburan atau wisata kota, dll.

d. Area dengan tingkat kepadatan manusia yang tinggi dan beragam.

e. Memiliki akses dari lalu - lintas utama.

\section{Analisa Tapak}

\section{SEGMENTASI RUAS JALAN HNGKAR KOTA TANUUNGPINANG}
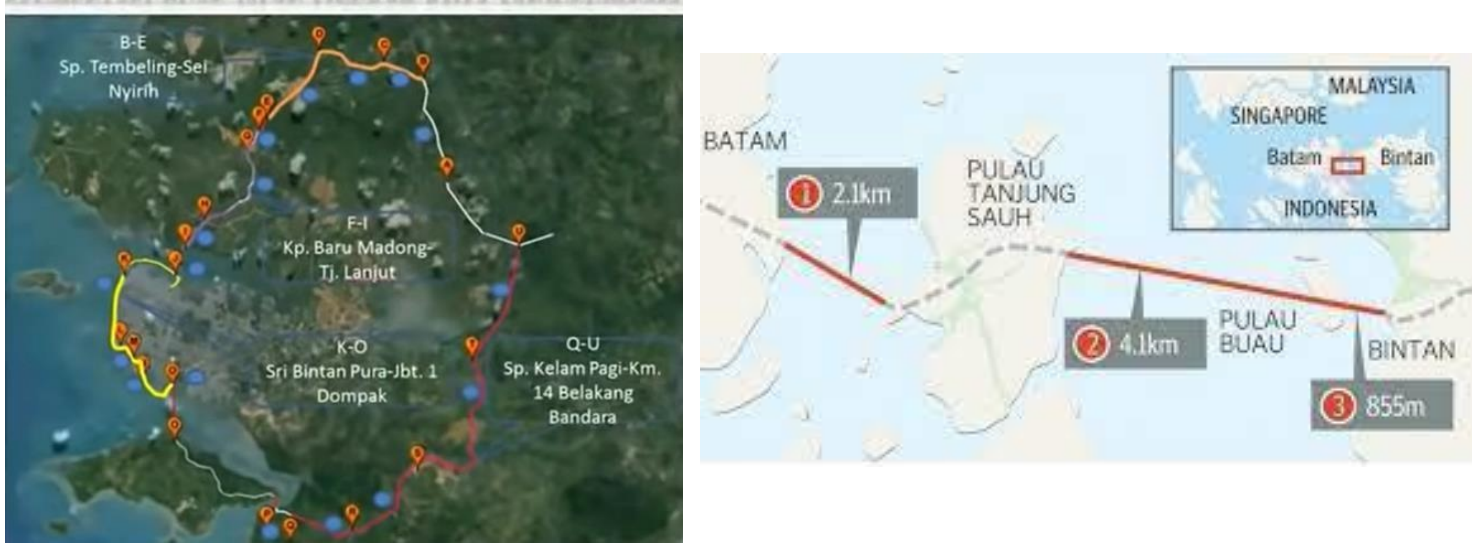

Gambar 5. Perancangan Akses Jalan Baru Pulau Bintan (Bintan-Batam).

Lokasi berada pada Jalan Agus Salim, Tanjung Pinang Barat, Kota Tanjung Pinang, Kepulauan Riau. Pada area Tepi Laut Tanjung Pinang, dan merupakan bagian dari perencanaan Gurindam 12. Area perancangan merupakan bagian zona investor dalam perancangan Gurindam 12, wilayah perancangan merupakan area yang di tata secara wilayah sebagai area Pariwisata, Campuran, Kuliner.Kawasan merupakan area yang sedang dalam pengembangan menjadi muka dari Tanjung Pinang, yang disekitar tapak memiliki fasilitas seperti ; masjid, panggung indoor, panggung outdoor, taman kota, dan pariwisata.

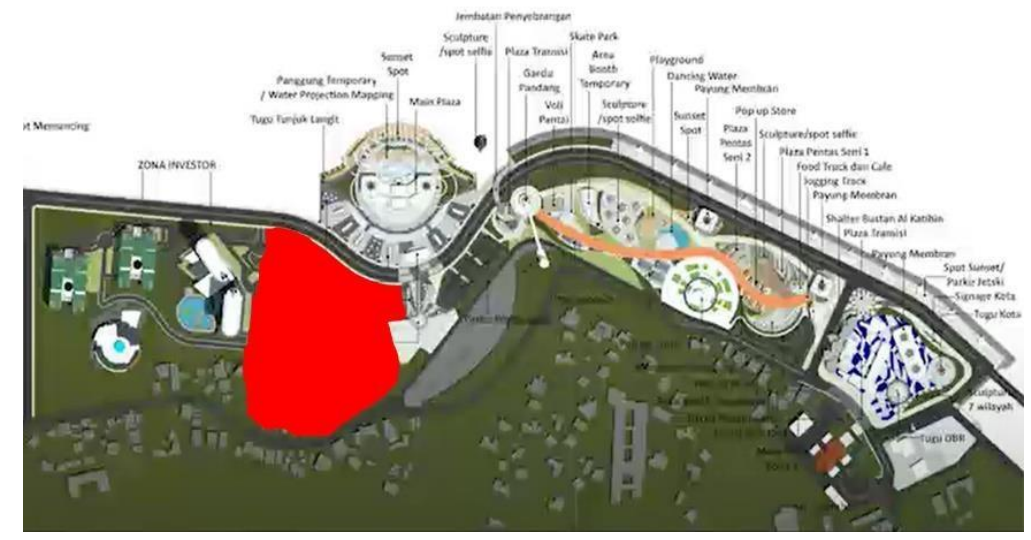

Gambar 6. Rancangan Area Sekitar Tapak.

Tanah perancangan seluas 5,2 $\mathrm{Ha}$, dan teletak diantara 2 jalan utama, pada bagian barat merupakan jalan tol lingkar Bintan, dan pada bagian timur merupakan jalan utama existing, yang merupakan jalan utama untuk wilayah Tanjung Pinang, untuk sekarang. Wilayah belum memiliki atau belum dipubliskan ke masyarakat, tentang standar KDH, KLB, KDB, DIl, sehingga penulis memperkirakan dengan mengikuti tata perancangan wilayah sekitar, yaitu ; KDB : 50\%, KDH : $50 \%, \mathrm{KLB}: 1,5, \mathrm{~KB}: 4$. 
Desain perpustakaan dengan pemanfaatan seperti skylight, dan bukaan-bukaan yang besar sehingga pencahayaan alami dapat masuk, serta view juga didapat. Kenyamanan menjadi kunci utama dalam mendesain perpustakaan terutama dalam hal kenyamanan membaca. Peletakkan posisi rak buku terhadap area membaca juga harus berdekatan.

\section{STRENGTHS}

- $\quad$-Tingginya Kepadatan Pengunjung

- $\quad$-Tingginya Kepadatan Lalu Lintas

- -Terdapat Pelabuhan, Masjid, Taman, Pelabuhan Domestik \& Internasional dibawah area $750 \mathrm{~m} 2$

- $\quad$-Area memiliki View Laut yang bagus, dan dapat melihat pulau yang bersejarah yaitu "pulau Penyengat"

\section{OPPORTUNITIES}

- $\quad$-Merupakan tempat yang dapat memikat pengunjung luar.

-Dapat menjadi area bagi wisatawan.

\section{WEAKNESS}

- $\quad$-Area berada di laut, yang pada siang dan sore, memiliki suhu yang relative tinggi. - Area rawan tindakan yang tidak baik, seperti pangkalan banci, pangkalan preman.

Tabel 1. SWOT Tapak.

\section{Program}

Program proyek ini bertujuan untuk memperkenalkan kembali tentang nilai - nilai adat, dan menggabungkan hal yang tradisional menjadi sesuatu yang baru yang tertanam dengan budaya dan tradisi dan gaya yang baru melalui arsitektur dan pemogramannya.

1. Museum

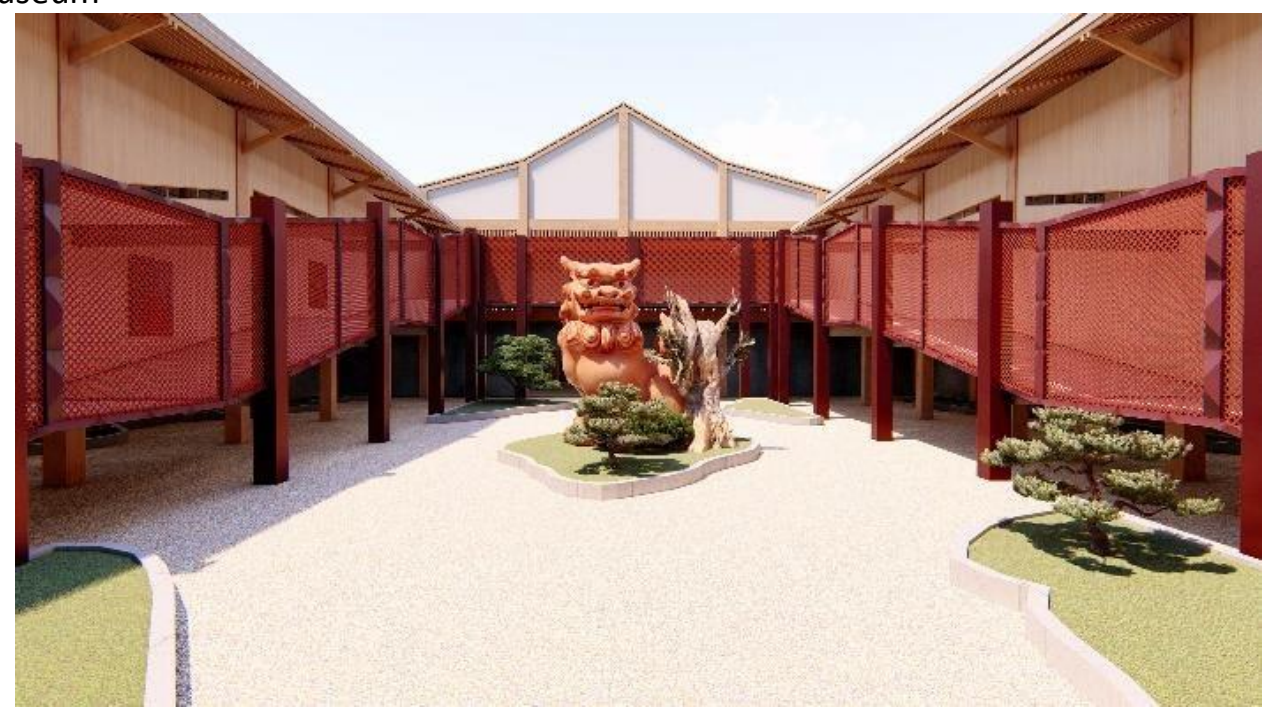

Gambar 7. Peta Kawasan Radius 3 km \& Peta Sekitar Tapak

Museum ini bertujuan untuk menampilkan cerita sejarahnya terbangun hubungan antar masyarakat, beserta dengan budaya dan tradisi yang diteruskan oleh leluhur pulau Bintan, Museum ini dibagi menjadi 2 bagian, bagian pertama yaitu lantai pertama merupakan openair museum, yang memiliki exhibition di bagian luar, menggunakan 
statue atau instalasi yang dapat ditaruh outdoor. Bagian ke 2 merupakan bagian lantai atas bangunan, merupakan gallery pada umunya yang berisi lukisan, patung, dan instalasi lainnya.

2. Perpustakaan

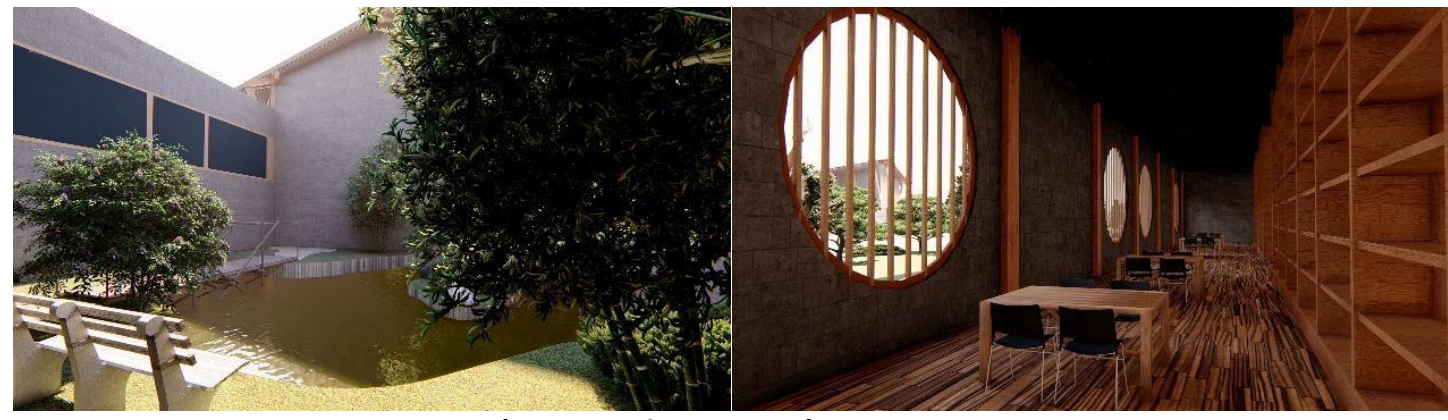

Gambar 8. Interior Perpustakaan.

Perpustakaan ini bertujuan untuk mengedukasikan masyarakat tentang budidaya membaca serta memberikan section yang berisi tradisi dan buadya yang menceritakan tentang sejarah, tata cara, dan kebiasaan yang ada pada suku yang ada di Bintan, terutama suku Tiong-Hoa, Melayu, dan Suku Laut.

3. Boutique Apparel Store

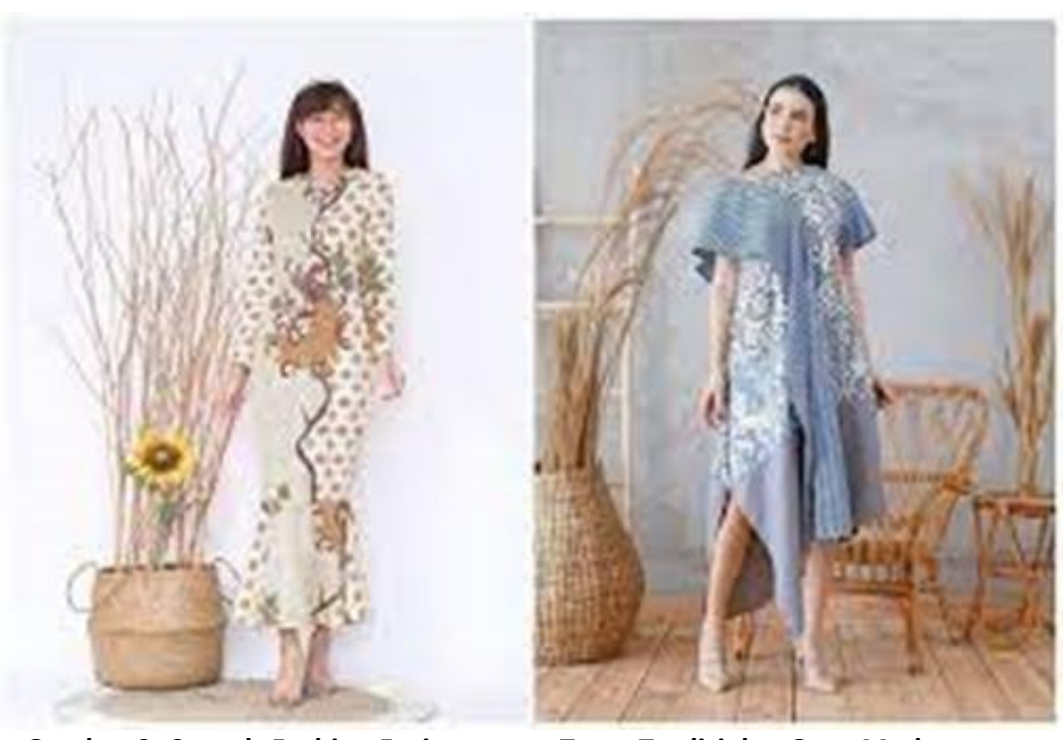

Gambar 9. Contoh Fashion Fusion antara Tema Tradisi dan Gaya Modern.

Tujuan program ini memberi muka baru pada gaya busana Bintan, yang bertujuan melakukan Fusion Fashion antara beberapa suku, atau juga dengan gaya busana modern yang ada. 
4. Bagian Komersial Bidang Kuliner (Pujasera dan Café)

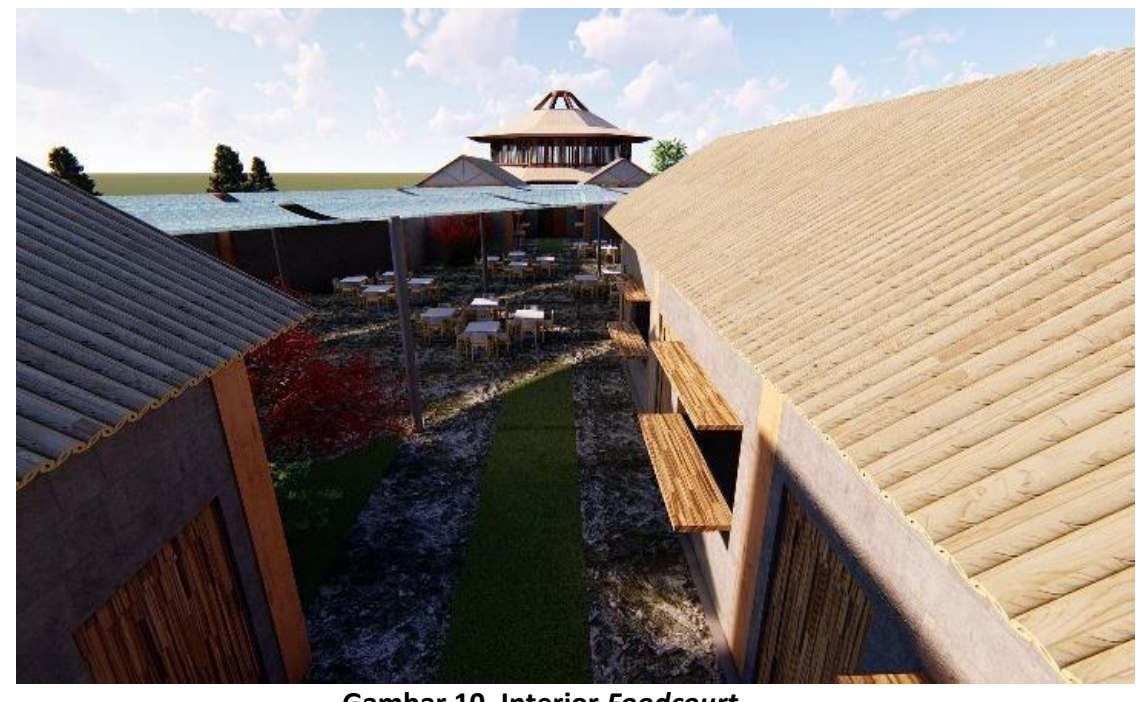

Gambar 10. Interior Foodcourt.

Tujuan Program ini mempertahankan dan mewariskan resep-resep citra kuliner Bintan dari beberapa suku, kepada masyarakat, dimana citra rasanya akan selalu turun dan temurunkan, serta memberikan rasa baru dengan menggabungkan kuliner tradisional dengan kuliner masa kini, ataupun menggabungkan rasa antara 2 atau lebih suku kedalam 1 hidangan makanan.

\section{Kesimpulan dan Saran Kesimpulan}

Manusia merupakan makhluk sosial dimana, kehidupannya adalah berinteraksi dengan manusia lainnya, yang menghasilkan kebiasaan dan kepercayaan yang akan diteruskan kepada keturunannya, dimana seiring zaman akan terjadi pemilahan dalam informasi yang telah didapatkan oleh setiap orang. Namun pada percepatan globalisasi dan era teknologi sekarang, semakin tinggi tingkat kepudaran yang terjadi dalam mempertahankan nilai - nilai dan norma yang menguntungkan, yang telah di salah artikan oleh masyarakat dan warga setempat, dan juga faktor eksternal yang mendukung tingginya ketidak pedulian atas nilai - nilai dan tradisi yang ada.

Munculnya berbagai program untuk meningkatkan tingkat kepedulian atas lingkungan sosial ini adalah untuk mempersatukan masyarkat melalui ekosistem sosial ini, dengan menggabungkan beberapa bagian suku menjadi satu wujud namun dengan tiap karakteristik berbeda mengajarkan masyarakat untuk memiliki tingkat toleransi yang tinggi, serta saling membantu/gotong. Seperti Museum untuk dan perpustakaan untuk memperkenalkan sejarah dan meng-edukasikan masyarakat awam tentang sejarah, kebiasaan dan nilai - nilai dari suku suku yang telah dibahas. Untuk mempreservasikan bangunan/rancangan menjadi bangunan yang mandiri akan ekonomi serta mengajarkan nilai - nilai suku tersebut, maka diperlukan komersial yang memiliki masukan.

Dengan rancangan ini, menjadi langkah pertama bagi daerah untuk menunjukan keaslian atau muka dari gaya perkembangan dan pertumbuhan, dari gaya arsitektur maupun aktivitas dari budaya dan tradisi daerah, yang dapat berkembang dengan percepatan zaman dan teknologi dalam globalisasi dan industri seperti negara - negara maupun kota - kota yang dikategorikan sebagai daerah maju (contoh : Jepang, Jerman, London, Shanghai, dl). Rancangan ini juga 
diharapan sebagai pemantik bagi warga setempat maupun daerah sekitarnya, untuk mengembangkan budaya dan tradisi yang ada.

\section{Saran}

Masih diperlukan penelitian dan data yang lebih akurat dengan survey langsung ke lokasi agar program dapat lebih realistis dan sistem peternakan dapat berjalan dengan baik. Data dan pembahasan harus dimatangkan lebih lanjut, untuk mendapatkan hasil dan statement yang lebih kuat, dan sebaiknya mengobservasi secara langsung dalam kurun waktu yang ditentukan, supaya dapat merasakan secara langsung dan memberikan solusi yang berdasarkan objektif, subyektif dan secara observasi lingkungan.

\section{REFERENSI}

Arman, D. (2018, Februari 19). Potret Orang Suku Laut di Kabupaten Bintan. Retrieved from Kementrian Pendidikan dan Kebudayaan Direktorat Jenderal Kebudayaan: https://kebudayaan.kemdikbud.go.id/bpnbkepri/potret-orang-suku-laut-dikabupaten-bintan/

Budaya Melayu . (2015, April 23). Retrieved from Bandar Seri Bintan: http://www.bandarseribentan.com/index.php?option=com_content\&view=article\&id $=382 \&$ Itemid $=155$

Dermawan, A.; Ismail, R Moh; Dasaluti, Tely; Darwis, Andi; Erlangga, Aulia; Raharja, Ganjar; Rizky, Arya; Kajang, Yayasan;. (2019). Suku Laut : Mengarungi Kehidupan Selingkar Sampan. Jakarta Pusat: Ditjen Pengelolaan Ruang Laur.

Frimansyah, R. (2016). Konsep Dasar Asimilasi dan Alkulturasi dalam Pembelajaran Budaya. Hidayat, M., Prayitno, B., \& Rahmi, D. H. (2020). Mix Methods for Ethnic Acculturation Study on History of Architectural Elements: Vernacular Houses during Pontianak Sultanate. ARSITEKTURA.

Prasetyo, A., Isjoni, \& Ibrahim, B. (2020). THE HISTORY OF TIONGHOA ETHNIC IN TANJUNGPINANG.

Savitri, P. L., Purbadi, Y. D., \& Sumardiyanto, B. (2020). Architectural Acculturation: Elements of Islamic and Janavese Spiritual Elements in Sumur Gumuling Design at Tamansari, Yogyakarta.

Sudarwani, M. M. (2017). Pendalaman Pengetahuan Arsitektur Nusantara.

Sutton, M. Q. (2009). Introduction to Cultural Ecology : 2nd (Second) Edition. Beritalima.

Zoer'aini., I., \& Djamal. (1992). Prinsip - prinsip Ekologi dan organisasi Ekosistem dan Lingkungan. 